(C) Asian Fisheries Society

ISSN 0116-6514

E-ISSN: 2073-3720

https://doi.org/10.33997/j.afs.2010.23.4.010

\title{
Development of rapid, simple and sensitive real-time reverse transcriptase loop-mediated isothermal amplification method (RT-LAMP) to detect viral diseases (PRDV, YHV, IHHNV and TSV) of penaeid shrimp
}

\author{
Raja Sudhakaran ${ }^{1}$, Tohru Mekata ${ }^{2,3}$, Mari Inada ${ }^{4}$, Shogo Okugawa ${ }^{4}$, \\ Tomoya Kono ${ }^{1}$, Kidchakan Supamattaya ${ }^{5}$, Terutoyo Yoshida ${ }^{1}$, Masahiro \\ Sakai $^{1}$, Toshiaki Itami ${ }^{1 *}$ \\ ${ }^{1}$ Faculty of Agriculture, University of Miyazaki, 1-1, Gakuen Kibanadai-nishi, 889-2192 \\ Miyazaki, Japan \\ ${ }^{2}$ Interdisciplinary Graduate School of Agriculture and Engineering, University of Miyazaki, 1-1, \\ Gakuen Kibanadai-nishi, 889-2192 Miyazaki, Japan \\ ${ }^{3}$ Aquatic Animal Health Division, National Research Institute of Aquaculture Fisheries Research \\ Agency, Saiki, 879-2602 Oita, Japan \\ ${ }^{4}$ Graduate School of Agriculture, University of Miyazaki, 1-1, Gakuen Kibanadai-nishi, 889- \\ 2192 Miyazaki, Japan \\ ${ }^{5}$ Faculty of Natural Resources, Prince of Songkla University, Hat Yai, Songkhla, 90110 \\ Thailand
}

\begin{abstract}
A one-step, single tube, real-time accelerated loop-mediated isothermal amplification (real-time LAMP) assay was developed separately to detect major shrimp viral diseases such as penaeid rod shaped DNA virus (PRDV), hypodermal and haematopoietic necrosis virus (IHHNV), Taura syndrome virus (TSV) and yellow head virus (YHV). Real-time LAMP method is more sensitive than other conventional PCR, RT-PCR and LAMP methods. The applicability of this assay was validated with plenty of viral samples collected from Japan and Thailand. Highly conserved regions of each viral genome developed separately were used to design the real-time LAMP primers. The real-time LAMP assay reported in this study is simple and rapid, where specific amplification is obtained for PRDV, IHHNV, TSV and YHV in 60 min under isothermal conditions at $63{ }^{\circ} \mathrm{C}$ employing six distinct sequences of the target gene. The quantification of viral load in the infected samples was determined from the standard curve based on their threshold time required for turbidity to occur in the reaction by precipitation of magnesium pyrophosphate. Sensitivity analysis revealed that all of these viruses can be detected up to 100 copies of template DNA, rendering it ten-fold more sensitive than conventional LAMP assay.
\end{abstract}

\footnotetext{
*Corresponding author. E-mail address: itamit@cc.miyazaki-u.ac.jp
} 


\section{Introduction}

Shrimp viral diseases are a major impediment to commercial shrimp farming. The diseases affecting shrimp culture are white spot syndrome virus (WSSV) or penaeid rod shaped virus (PRDV), yellow head virus (YHV), infectious hypodermal and hematopoietic necrosis virus (IHHNV) and Taura syndrome virus (TSV). PRDV of shrimp was first discovered in northern Taiwan around 1992 and is currently the most serious viral pathogen in farm reared Marsupenaeus japonicus (Nakano et al. 1994; Takahashi et al. 1994) throughout the world (Chou et al. 1995; Lo et al. 1996; Flegel 1997). The International Committee on Taxonomy of Viruses (ICTV) determined PRDV is the type species of the genus Whispovirus, family Nimaviridae (Mayo 2002). The typical clinical signs of PRDV include lethargy, reduced food intake and the appearance of white spots on the carapace (Lightner 1996). This virus causes 100\% mortality within 3 to 10 days in all life stages of both wild and cultured Penaeus monodon and $M$. japonicus, and has a wide host range which includes penaeid shrimp, crabs, copepods and other arthropods (Chen et al. 2000; Syed Musthaq et al. 2006).

YHV was first reported as a virulent pathogen in the early 1990's causing a $100 \%$ crop loss within 3 to 5 days post-infection in P. monodon in Thailand (Limsuwan 1991 ; Chantanachookin et al. 1993). Since then, several researchers have reported the occurrence of YHV in farmed and wild shrimp in Taiwan and many other Asian countries. The causative agent is a rod-shaped, enveloped virus with positive stranded ssRNA containing four open reading frames classified under the genus Okavirus, family Ronivirida. So far, six genotypes have been identified and only genotype 1 is known to cause typical signs of YHV infection in shrimp. Other genotypes have been found to be widespread in $P$. monodon shrimp populations throughout the Indo-Pacific region, but have not been associated with farm disease outbreaks (Wijegoonawardane et al. 2008).

IHHNV is a cosmopolitan virus infecting penaeid shrimp in the Asian-Pacific area and the Americas, but it is not reported in Japan. The virus causes $90 \%$ mortality in P. stylirostris juveniles (Lightner et al. 1983) and is detected in other penaeid shrimps (Flegel 1997). The typical symptoms of the viral disease include reduction in growth and a runt deformity (Lightner et al. 1992; Primavera and Quinitio 2000). The virions of IHHNV are non-enveloped icosahedrons (22 $\mathrm{nm}$ in diameter) containing a singlestrand linear DNA of $4.1 \mathrm{~kb}$ (Bonami et al. 1990). Genome homology suggests IHHNV may be related to mosquito Brevidensovirus (Shike et al. 2000). Taura syndrome virus (TSV) is a causative agent of Taura syndrome, a major disease of the white leg shrimp, P. vannamei. TSV was originally placed in the family Picornaviridae, but was later transferred to the Dicistroviridae. The complete TSV genome is a linear, positive-sense, 
single stranded RNA virus of 10,205 bases. Taura syndrome was first recognized in shrimp farming in Ecuador in mid-1992. The loss was estimated to be close to US\$100 million. Although the TSV originated in Ecuador, it was subsequently discovered in Taiwan in 2000.

Viral diseases are particularly difficult to control after the onset of infection; therefore, prophylaxes to prevent or reduce the losses through vertical and horizontal transmission are most important (Bell and Lightner 1988; Lotz 1997). Various diagnostic methods have been developed to detect shrimp viral diseases, including bioassays, histopathology, dot blot with in situ hybridization, polymerase chain reaction (PCR) (Lightner and Redman, 1998) and quantitative real-time PCR (Tang and Lightner 2001). Although the PCR based methods are sensitive and highly specific, they require expensive equipment, costly reagents and are time consuming. Therefore, a simple, quick and quantitative detection method is urgently needed to prevent the invasion of shrimp viral diseases into Japan from other countries. The LAMP assay is a novel approach to nucleic acid amplification that amplifies DNA with high specificity, selectivity and rapidity under isothermal conditions, thereby obviating the need for a thermal cycler. The LAMP assay is based on the principle of autocycling strand displacement DNA synthesis (Notomi et al. 2000). The reaction is performed by DNA polymerase with strand displacement activity and two sets of specially designed inner and outer primers. This assay is highly specific for the target sequence, because the target sequence is recognized at six independent sequences in the initial stage and at four independent sequences during the later stages of the LAMP reaction. The LAMP method has been used without quantitation for diagnosis of various shrimp viruses, such as WSSV (Kono et al. 2004), YHV (Mekata et al. 2006), MrNV \& XSV (Pillai et al. 2006), infectious hypodermal and hematopoietic necrosis virus (IHHNV) (Sun et al. 2006) and TSV (Kiatpathomchai et al. 2007). These qualitative methods, however, cannot determine the copy number of the viral particles present in the sample.

Real time loop mediated isothermal amplification (RT-LAMP) assay produces large amounts of the target DNA as well as an insoluble by-product, magnesium pyrophosphate, during the reaction, making it possible to perform a real-time measurement of turbidity using an inexpensive photometer (Mori et al. 2001). Realtime LAMP assay has been used for many non-shrimp viruses, such as West Nile virus (Parida et al. 2004), severe acute respiratory syndrome (SARS) virus (Poon et al. 2005), dengue virus (Parida et al. 2005) and hepatitis A virus (Yoneyama et al. 2007). In the present study, a comparatively less expensive quantitative real-time RT-LAMP assay was successfully applied for detection of shrimp viral diseases in the field and proven to have high sensitivity and specificity. 


\section{Materials and Methods}

\section{Shrimp}

Black tiger shrimp (P. monodon) and white leg shrimp (L. vannamei) with prominent signs of PRDV, YHV infection and IHHNV, TSV infection respectively were collected from shrimp farms in Songkhla, Thailand and Miyazaki, Japan. Shrimp samples were collected in separate sterile tubes and transported to the laboratory on dry ice for the RT-LAMP assay for each viral pathogen.

\section{Nucleic acid extraction}

Extraction of DNA was performed from the corresponding viral homogenates prepared from PRDV and IHHNV sources. From each sample, $200 \mu \mathrm{L}$ of the homogenate was added to $600 \mu \mathrm{L}$ of DNAzol reagent (Invitrogen, Carlsbad, CA, USA) and further steps were carried out according to the manufacturer's instructions. Total RNA was extracted from a pool of heart tissues from the infected shrimp using an RNA extraction kit (High Pure RNA Tissue Kit; Roche Diagnostics, Germany) according to the manufacturer's instructions. Extracted nucleic acid samples were quantified using Nanodrop UV Spectrophotometer ND-100 (NanoDrop Technologies, USA). Synthesis of cDNA for quantitation analysis was carried out using ReverTra Ace qPCR RT Kit (Toyobo, Japan) with $1 \mu \mathrm{g}$ of total RNA as per the manufacturer's instructions.

\section{Design of primers for real-time LAMP procedures}

RT-LAMP primers specific to PRDV, YHV, IHHNV and TSV were designed according to the published sequences using Primer Explorer Software version 4 (https://primerexplorer.jp/lamp4.0.0/index.html, Fujitsu, Japan). The target regions of each shrimp viral pathogen include: ORF36 of PRDV, replicase polyprotein gene of YHV, non-structural protein of IHHNV and coat protein gene of TSV (GenBank Accession No. AF369029, EU487200, AF218266 and AF277378 respectively). A set of four primers, two outer (F3 and B3) and two inner primers (FIP and BIP), were designed according to the guideline provided. The oligonucleotide primers used for the amplification are shown in Table 1. Each primer has two distinct sequences corresponding to the sense and antisense sequences of the target: one for priming in the first stage and the other for self-priming in later stages. The specific primer regions were selected because of their early expression following the specific viral pathogen invasion. 
Table 1. Primers used for the RT-LAMP assay for diagnosis of PRDV, YHV, IHHNV and TSV

\begin{tabular}{ll}
\hline Primer name & Sequence 5'-3' \\
\hline WSDV-FIP & TCCGTCTTCAGGGAATACATATGCTCAGGGAAGAAATAGACCATG \\
WSDV-BIP & GGACCCAAATCGAAATATAAGGCCTATGTTGCCCAAGATCCAC \\
WSDV-F3 & AAACACCGGATGGGCTAA \\
WSDV-B3 & CAAGGCAATACAGAATGCG \\
& \\
YHV-FIP & GACGTGTGGATGCATAAATTTCATGTATCAAATTTTCCTTGAACCTGG \\
YHV-BIP & CGATTGCCGTTACAACATGATGTTGGAATGGTCTCATGAAGG \\
YHV-F3 & TTCCGTAATGCCGGTGAT \\
YHV-B3 & AACGCTAGGAGTATAACCG \\
& \\
IHHNV-FIP & GAAAACTGGAACAGTTCTTCAGACAAATCAAGACCCTAAACCCAC \\
IHHNV-BIP & ACGAGGAAGACAACTCTCAAACTGTTATCCACGCAGACCTTAG \\
IHHNV-F3 & TCTCCAAGCCTTCTCACC \\
IHHNV-B3 & TCCCTCTCGAATTCCCAG \\
& \\
TSV-FIP & AGTTCATCTCAATGCCAGGAAATGAAGACATCAATTATTCGACGC \\
TSV-BIP & GCAGTCTGAAGCTCGAGCTATTGTTATTCACATTTCTGGGGTT \\
TSV-F3 & TGGAATAAGATGAATGCTAAGC \\
TSV-B3 & GACTCAGAACGGAAAGCC \\
\hline
\end{tabular}

Optimization of reaction time and temperature

The real-time RT-LAMP was carried out in a total volume of $25 \mu \mathrm{L}$ of reaction mixture using Loopamp DNA and RNA Amplification Kit (Eiken Chemical, Japan) according to the manufacturer's instructions for analysis of DNA and RNA viruses respectively. Briefly, the specified amount of target nucleic acid was mixed with $1 \mu \mathrm{L}$ (40 pmol) of each -FIP and -BIP, $1 \mu \mathrm{L}(5 \mathrm{pmol})$ of -F3 and -B3 primers, $12.5 \mu \mathrm{L}$ of Reaction Mix (2×), $1 \mu \mathrm{L}$ Enzyme Mix containing Bst DNA polymerase and distilled water used to make up to $25 \mu \mathrm{L}$. AMV reverse transcriptase was used in the case of YHV and TSV. The reaction temperature $\left(60,63\right.$ and $\left.65^{\circ} \mathrm{C}\right)$ was optimized using Loopamp Real Time Turbidimeter LA-200C (Teramecs, Japan). Real-time monitoring was performed every $6 \mathrm{sec}$ using spectrophotometric analysis by recording the optical density (OD) at $650 \mathrm{~nm}$. Each assay was carried out three times.

\section{Determination of sensitivity of real-time RT-LAMP assay}

Ten-fold serial dilutions $\left(10^{-1}\right.$ to $\left.10^{-9}\right)$ of nucleic acids extracted from various shrimp viral diseases were used as templates for RT-LAMP under the optimized conditions. RT-LAMP reaction was performed using the Loopamp real-time turbidimeter. 


\section{Specificity of real-time RT-LAMP detection}

The specificity of the RT-LAMP method was evaluated using different sources of DNA/cDNA templates prepared from YHV-, PRDV-, IHHNV- and TSV-infected shrimp and healthy shrimp. Each assay was carried out in duplicate.

\section{Quantitative real-time RT-LAMP}

To determine the quantity of unknown nucleic acid using the RT-LAMP assay, the specific target fragments of each viral disease were cloned into plasmid. The amplified PCR product was cloned into pGEM-T Easy Vectors (Promega, USA) according to the manufacturer's instructions. Quantitation of the constructed plasmid (using pGEM vector) was achieved using the NanoDrop spectrophotometer, and tenfold serial dilutions $\left(10^{1}\right.$ to $\left.10^{9}\right)$ were made to evaluate the real-time LAMP assay. The copy numbers of the plasmid DNA were calculated based on the molecular weight and Avogadro's number, and a standard curve was constructed. The standard curve of the specific virus was generated each time during the analysis of samples. The reaction setup was the same as that optimized above, and the reactions were carried out in the Loopamp real-time turbidimeter.

\section{Results}

Optimization of real-time RT-LAMP assay conditions for PRDV, YHV, IHHNV \& TSV detection

RT-LAMP was performed using DNA/RNA as a template in order to determine the optimal temperature and reaction time for various shrimp viral pathogen. Out of the three different temperatures $\left(60,63\right.$ and $\left.65^{\circ} \mathrm{C}\right)$, the best results were obtained at $63{ }^{\circ} \mathrm{C}$. The most rapid amplification was achieved at this temperature, requiring less than 20 min for the initiation of amplification as determined by a change in the turbidity by magnesium pyrophosphate (Fig. 1). Amplification was efficient at all temperatures tested; however, $63{ }^{\circ} \mathrm{C}$ for $60 \mathrm{~min}$ of reaction time was selected as optimal conditions for further experiment. 


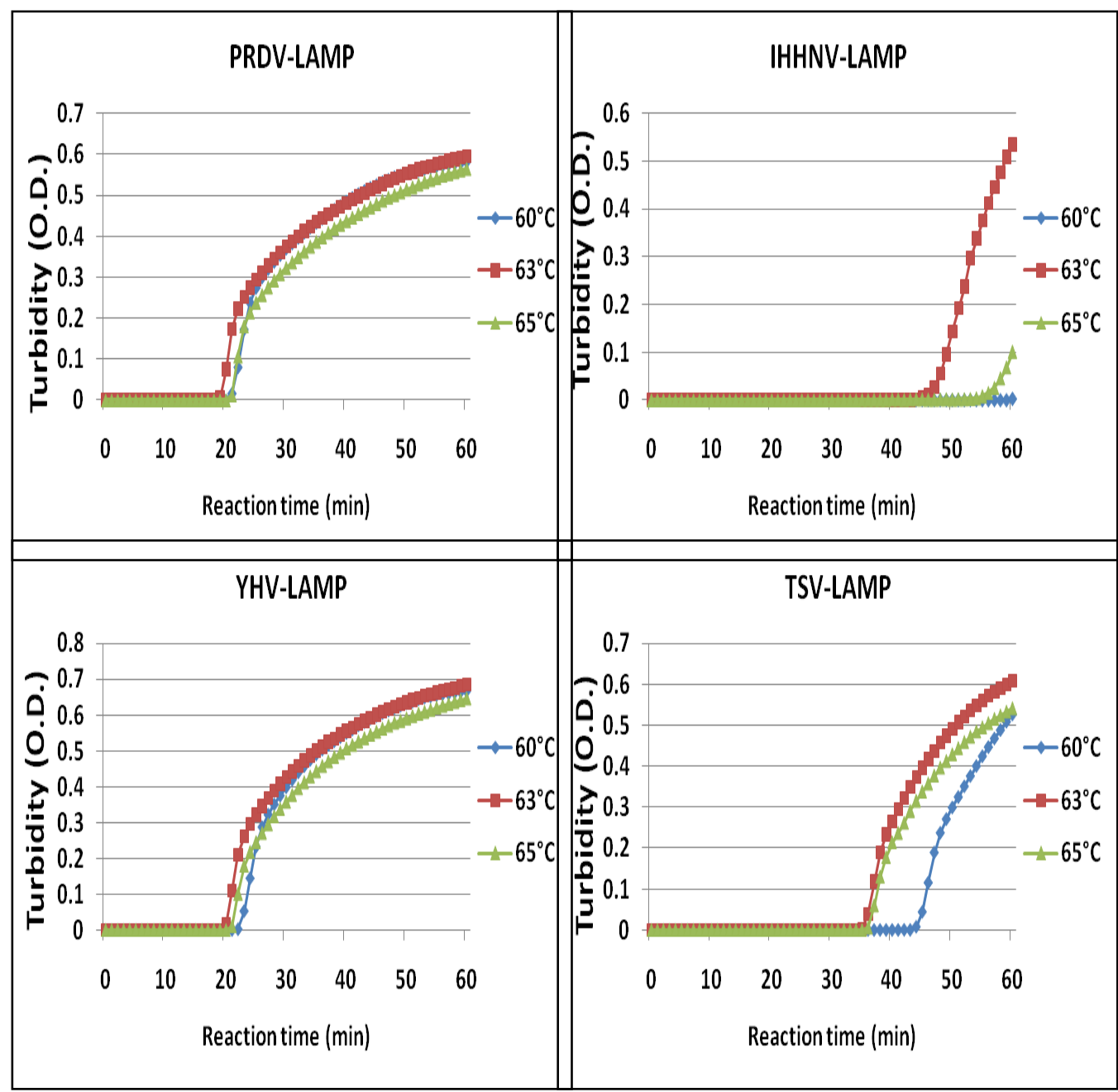

Fig. 1. Optimization of the reaction temperature for RT-LAMP assay of shrimp viral pathogens (PRDV, YHV, IHHNV and TSV) performed at 60, 63 and $65^{\circ} \mathrm{C}$.

\section{Specificity of RT-LAMP detection}

Cross-reactivity analysis was performed to examine the specificity of real-time RT-LAMP assay. DNA/cDNA of other shrimp viral disease viruses (PRDV, YHV, IHHNV and TSV) and healthy shrimp were used to determine the specificity of each viral diagnostic assay using RT-LAMP assay. As shown in Fig. 2, the RT-LAMP assay was highly specific to each virus without any cross-reaction with other shrimp viral pathogens. 


\section{Quantitative detection using RT-LAMP}

For quantitative detection of samples of unknown concentrations, a standard curve was generated using the turbidity time $(\mathrm{Tt})$ plotted against the log of the initial template using serially diluted, $10^{1}$ to $10^{9}$ copies $^{\prime} \mathrm{L}^{-1}$ of plasmids with inserts of concern viral target DNAs (Fig. 3). High correlation coefficient values $\left(R^{2}=0.99, R^{2}=\right.$ $0.99, R^{2}=0.98$ and $R^{2}=0.99$ respectively for PRDV, YHV, IHHNV and TSV) were obtained for each viral pathogen by using real-time LAMP assay (Fig. 4). Ten-fold dilutions were used to generate standard curves for each pathogen to run in parallel with unknown samples for quantitative and diagnostic analysis.

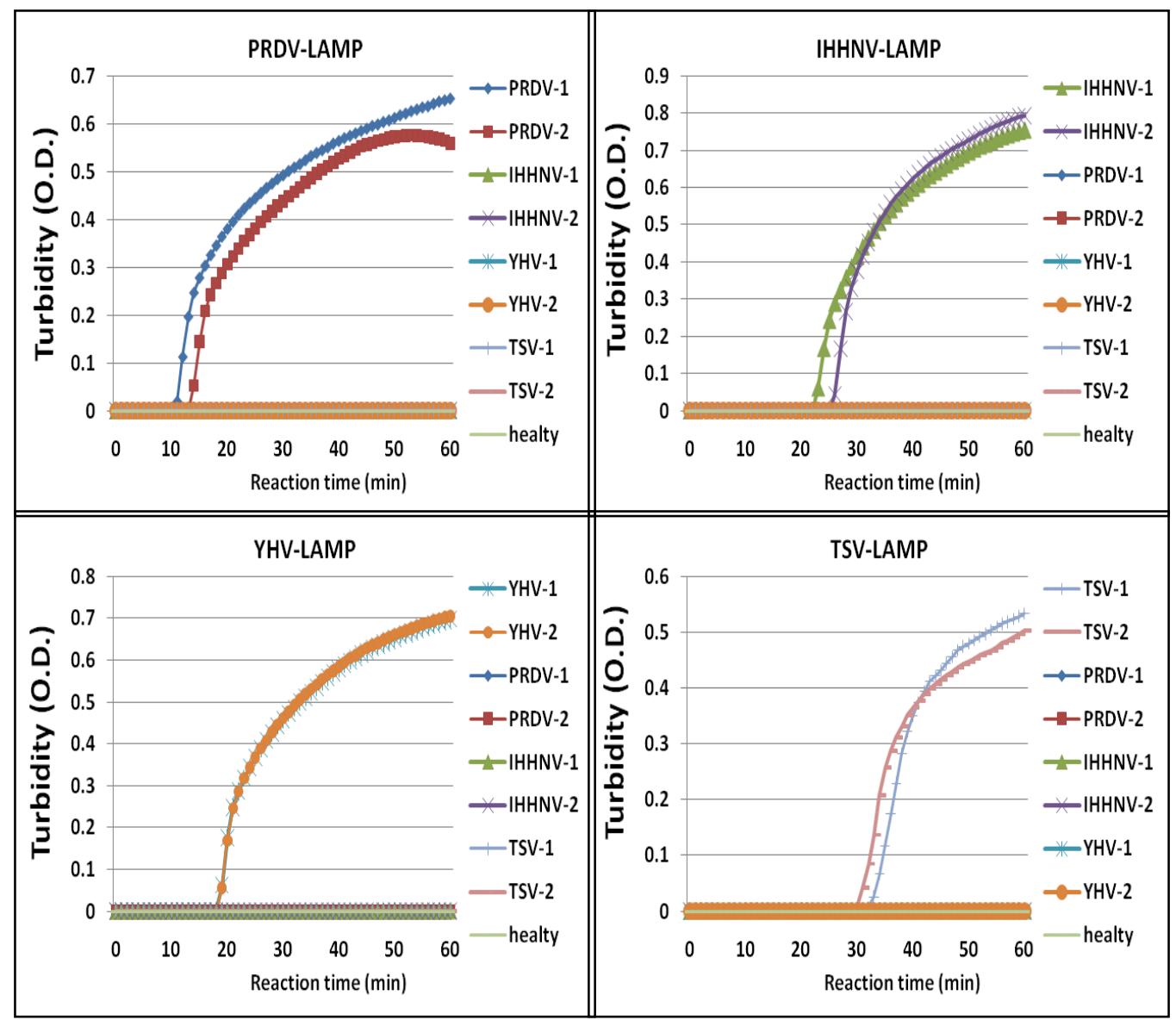

Fig. 2. Specificity of the RT-LAMP assay. Results of cross-reaction analysis with templates of individual shrimp pathogen with other major shrimp viruses (PRDV, YHV, IHHNV and TSVDNA/cDNA) and with a healthy shrimp DNA template are shown. 


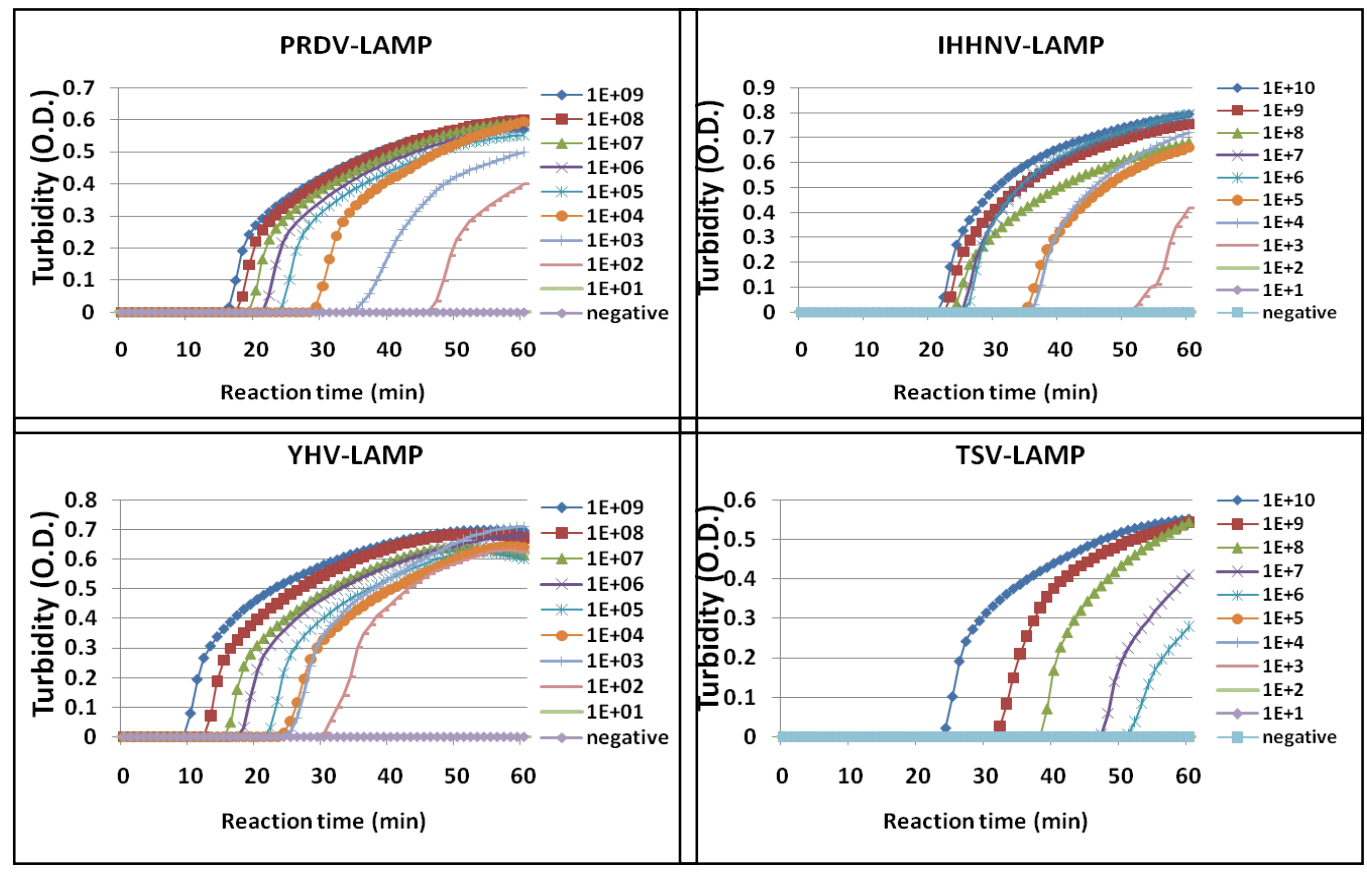

Fig. 3. Real - time amplification of shrimp viral pathogens (PRDV, YHV, IHHNV and TSV) using RT-LAMP assay. Plasmid standards corresponding to target gene of each shrimp viral pathogen at concentrations of $10^{1}$ to $10^{9}$ copies $^{*} \mathrm{~L}^{-1}$ (time is shown on the $\mathrm{X}$-axis and OD at 650 nm on the Y-axis).

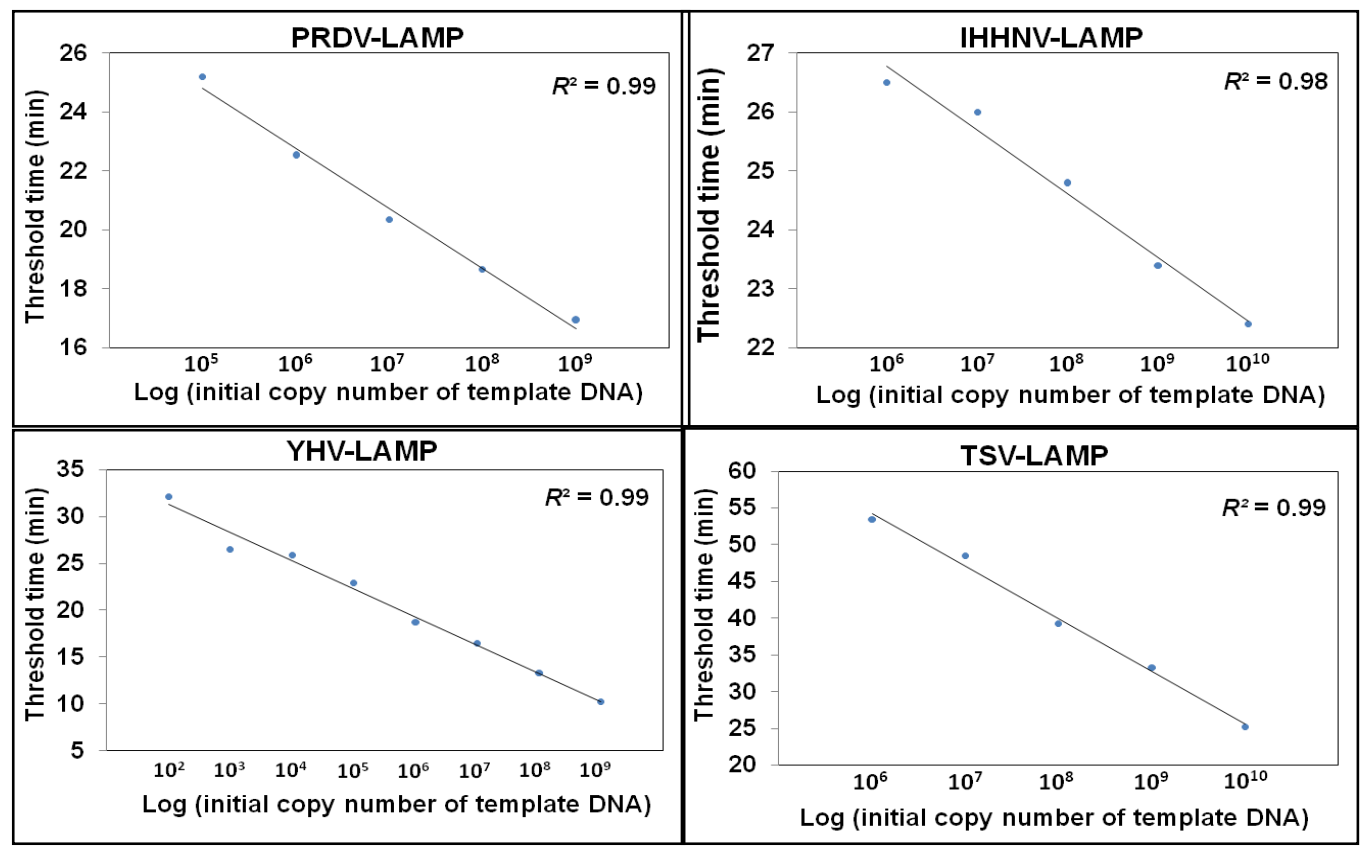

Fig. 4. Real - time amplification of shrimp viral pathogens (PRDV, YHV, IHHNV and TSV) using RT-LAMP assay. Standard curves generated from plasmid standards corresponding to target gene of each shrimp viral pathogens. 


\section{Discussion}

Recent outbreaks of IHHNV, YHV and TSV virus in the Asia-Pacific area and other regions have caused severe economic loss to shrimp farmers; however, these viral disease outbreaks have not been reported in Japan. Therefore, these diseases have been designated as "a specified disease" using Japanese law, where if the disease is detected in Japan, all shrimp must be destroyed to prevent wide spread dissemination. Therefore, it is essential to develop an efficient method for field surveillance for these pathogens which has high specificity and sensitivity with a short reaction time, as well as the ability to quantify the viral load. A recent outbreak of YHV in the Asia-Pacific and other regions has led to severe economic loss to shrimp farmers (Cowley and Walker 2002) because there was no user-friendly detection assay available.

Here we demonstrate a new diagnostic method for the quantitative detection of shrimp viral pathogens (PRDV, YNV, IHHNV, TSV) using the real-time LAMP method. Early detection of shrimp viral pathogens is important in the shrimp industry for effective health management and preventive measures. Previously, various nucleic acid and protein based assays (Sritunyalucksana et al. 2006) have been employed for the detection of WSSV and other shrimp viral pathogens in the shrimp culture sector. All of these assays can determine only the presence of viral pathogen; however, they do not determine the number of virus particles present. Quantification of WSSV can be achieved by real-time PCR assays using Taqman (Sritunyalucksana et al. 2006) and SYBR chemistry (Khadijah et al. 2003; Yuan et al. 2007).

Various conventional diagnostic methods for WSSV have been developed and reported by several researchers worldwide with different sensitivity. Sensitivity of the normal qualitative LAMP assay of WSSV was almost equal to the RT-LAMP assay, whereas it lacks quantitative measurement (Kono et al. 2004). Different PCR-based assays such as one step PCR, nested PCR, real-time PCR have the sensitivity limit of up to 1000 copies, 50 copies and five copies, respectively (Sritunyalucksana et al. 2006). In contrast, the RT-LAMP method is found to be a cost-effective quantitative assay for shrimp viral disease diagnosis. As all conventional methods were developed based on a specific genome, the chance of non-specificity is found to be much less. Real-time RTPCR assays have been developed for laboratory diagnosis of shrimp viruses; however, these techniques have the intrinsic disadvantage of requiring both high-precision instrument, high costs for amplification and a complex method for the detection of amplified products and technically qualified persons.

The increased need for an inexpensive method to quantify shrimp viral pathogens led us to develop the RT-LAMP method. Also the cost of the LoopAmp 
turbidimeter is low, whereas the real-time PCR assays require fluorogenic primers and probes using an expensive fluorometer (Parida et al. 2004). The sensitive RT-LAMP assay has been successfully applied to detect many human pathogenic RNA viruses, resulting in rapid and simple diagnostic measures. The rapid simple detection and quantification of shrimp viral pathogens using RT-LAMP take less time when compared to other PCR and real-time PCR methods. The optimum conditions for the real-time LAMP reaction were $63{ }^{\circ} \mathrm{C}$ for $60 \mathrm{~min}$. Higher temperatures can support the rigorous binding of primer and target template in the LAMP reaction than at lower temperatures (Teng et al. 2007), leading to amplicons consisting of concatemer hairpin repeats (Cai et al. 2008). Using the optimized conditions to perform the assay in a short period of time ( $<60 \mathrm{~min}$ ), the turbidity caused by the magnesium pyrophosphate can be visualized without an instrument (Sun et al. 2006). This assay will provide a practical tool in the field for quantitative detection of viral infection in cultured shrimp, even at the early stages.

Each virus-specific standard curve was generated using 10 -fold dilutions of $10^{1}$ $-10^{9}$ copies $\mu \mathrm{L}^{-1}$ of purified plasmids and the reactions were run in duplicate. The mean $\mathrm{T}_{\mathrm{t}}$ for the plasmid standards was generated using the specific software provided with the Loopamp real-time turbidimeter. Standard curve equations were calculated using regression analysis, which compared the average $\mathrm{Tt}$ to the standard copy number. We obtained a high correlation coefficient (greater than or equal to $\mathrm{R}^{2}=0.988$ for each shrimp viral pathogens) for the unknown quantity DNA templates. Cross reactivity analysis showed the primers used were specific to each viral pathogen and did not amplify for other shrimp viral pathogens and healthy shrimp cDNA/DNA templates. Sensitivity analysis showed the assay for each shrimp viral pathogen is detectable up to 100 copies of the template DNA, which is more sensitive than the earlier-developed LAMP and PCR based methods. Furthermore, the gradual decrease of turbidity in the reaction was also clearly observed by the naked eye.

The RT-LAMP assay is an alternate method to conventional PCR and the LAMP assay (Sun et al. 2006) and in addition, it quantifies the shrimp viral nucleic acid templates. This gives a triplex amplification synchronization on one target gene (Cai et al. 2008). The RT-LAMP assay allows positive samples to become clouded (turbid) and can be viewed visually, eliminating electrophoresis for further confirmation (Mori et al. 2004). The sensitivity of the loop primer was demonstrated in a previous report (Nagamine et al. 2002). The real-time quantitative LAMP assay can be used for gene expression analysis, as the reaction is performed under isothermal conditions and a relatively low temperature where the reverse transcriptase can efficiently work. Thus, this assay has the potential to simplify quantitative gene expression analysis. 
Therefore, we believe the genome specific RT-LAMP assay will be routinely used as a comprehensive shrimp viral detection system in most field diagnostic laboratories because of its speed, simplicity, specificity and lower cost. We are considering further studies using RT-LAMP with the fluorescence probe, SYBR-I, as the intercalation dye to increase the LAMP sensitivity to quantify very low numbers of virus. The RT-LAMP assay would be a promising technology for shrimp viral pathogen detection, which contributes to better shrimp health management and disease surveillance in shrimp hatcheries and culture ponds for prevention of disease outbreak.

\section{Acknowledgements}

R. Sudhakaran and T. Mekata are recipients of the Japan Society of Promotion of Science (JSPS) postdoctoral fellowships for foreign researchers and research fellowships for young scientists. This study was supported, in-part, by research Grantin-Aid for Scientific Research from JSPS and the Development Program for New Bioindustry Initiatives of Japan.

\section{References}

Bell, T.A. and D. V. Lightner. 1988. A Handbook of normal penaeid shrimp histology. World Aquaculture Society, Baton Rouge, LA, USA.114 pp.

Bonami, J.R., B. Trumper, J. Mari, M. Brehelin and D. V. Lightner. 1990. Purification and characterization of the infectious hypodermal and haematopoietic necrosis virus of penaeid shrimps. Journal of General Virology 71:2657-2664.

Cai, T., G. Lou, J. Yang, D. Xu and Z. Meng. 2008. Development and evaluation of real-time loop-mediated isothermal amplification for hepatitis B virus DNA quantification: A new tool for HBV management. Journal of Clinical Virology 41:270-276.

Chantanachookin, C., S. Boonyaratpalin, J. Kasornchandra, S. Direkbusarakom, U. Aekpanithanpong, K. Supamattaya, S. Sriuraitana and T.W. Flegel. 1993. Histology and ultrastructure reveal a new granulosis-like virus in Penaeus monodon affected by yellow-head disease. Diseases of Aquatic Organisms 17:145-157.

Chen, L.L., C.F. Lo, Y.L. Chiu, C.F. Chang and G.H. Kou. 2000. Natural and experimental infection of white spot syndrome virus (WSSV) in benthic larvae of mud crab Scylla serrata. Diseases of Aquatic Organisms 40:157-161.

Chou, H.Y., C.Y. Huang, C.H. Wang and C.F. Lo. 1995. Pathogenicity of a baculovirus infection causing white spot syndrome in cultured penaeid shrimp in Taiwan. Diseases of Aquatic Organisms 23:165-173.

Cowley, J.A. and P.J. Walker. 2002. The complete genome sequence of gill-associated virus of Penaeus monodon prawns indicates a gene organisation unique among nidoviruses. Archives of Virology 147:1977-1987.

Flegel, T.W. 1997. Major viral diseases of the black tiger prawn (Penaeus monodon) in Thailand. World Journal of Microbiology and Biotechnology 13:433-442. 
Khadijah, S., S.Y. Neo, M.S. Hossain, L.D. Miller, S. Mathavan and J. Kwang. 2003. Identification of white spot syndrome virus latency-related genes in specific-pathogenfree shrimps by use of a microarray. Journal of Virology 77:10162-10167.

Kiatpathomchai, W., W. Jareonram, S. Jitrapakdee and T.W. Flegel. 2007. Rapid and sensitive detection of Taura syndrome virus by reverse transcription loop-mediated isothermal amplification. Journal of Virological Methods 146:125-128.

Kono, T., R. Savan, M. Sakai and T. Itami. 2004. Detection of white spot syndrome virus in shrimp by loop-mediated isothermal amplification. Journal of Virological Methods 115:59-65.

Lightner, D.V. (ed.) 1996. A Hand Book of Shrimp Pathology and Diagnostic Procedures for Diseases of Cultured Penaeid Shrimp. World Aquaculture Society, Baton Rogue, LA. $304 \mathrm{pp}$.

Lightner, D.V., T.A. Bell, R.M. Redman, L.L. Mohney, J.M. Natividad, A. Rukyani and A. Poernomo. 1992. A review of some major diseases of economic significance in penaeid prawns/shrimps of the Americas and Indopacific. In: Diseases in Asian Aquaculture-Fish Health Section (ed. M. Shariff, R.P. Subasinghe and J.R. Arthur), pp. 57-80. Asian Fisheries Society, Manila, Philippines.

Lightner, D.V. and R.M. Redman, 1998. Shrimp diseases and current diagnostic methods. Aquaculture 164:201-220.

Lightner, D.V., R.M. Redman and T.A. Bell. 1983. Infectious hypodermal and hematopoietic necrosis, a newly recognized virus disease of penaeid shrimp. Journal of Invertebrate Pathology 42:62-70.

Limsuwan, C. 1991. Handbook for cultivation of black tiger prawns. Tansetakit Co., Ltd., Bangkok (in Thai).

Lo, C.F., C.H. Ho, S.E. Peng, C.H. Chen, H.C. Hsu, Y.L. Chiu, C.F. Chang, K.F. Liu, M.S. Su, C.H. Wang and G.H. Kou. 1996. White spot syndrome baculovirus (WSBV) detected in cultured and captured shrimp, crabs and other arthropods. Diseases of Aquatic Organisms 27:215-225.

Lotz, J.M. 1997. Special topic review: viruses, biosecurity and specific pathogen-free stocks in shrimp aquaculture. World Journal of Microbiology and Biotechnology 13:405-413.

Mayo, M.A. 2002. A summary of taxonomic changes recently approved by ICTV. Archives of Virology 147:1655-1663.

Mekata, T., T. Kono, R. Savan, M. Sakai, J. Kasornchandra, T. Yoshida and T. Itami. 2006. Detection of yellow head virus in shrimp by loop-mediated isothermal amplification (LAMP). Journal of Virological Methods 135:151-156.

Mori, Y., K. Nagamine, N. Tomita and T. Notomi. 2001. Detection of loop-mediated isothermal amplification reaction by turbidity derived from magnesium pyrophosphate formation. Biochemical and Biophysical Research Communications 289:150-154.

Mori, Y., M. Kitao, N. Tomita and T. Notomi. 2004. Real-time turbidimetry of LAMP reaction for quantifying template DNA. Journal of Biochemical and Biophysical Methods 59:145-157.

Nagamine, K., T. Hase and T. Notomi. 2002. Accelerated reaction by loop mediated isothermal amplification using loop primers. Molecular and Cellular Probes 16:223-229.

Nakano, H., H. Koube, S. Umezawa, K. Momoyama, M. Hiraoka, K. Inouye and N. Oseko. 1994. Mass mortalities of cultured kuruma shrimp, Penaeus japonicus, in Japan in 1993: epizootilogical survey and infection trials. Fish Pathology 29:135-139. 
Notomi, T., H. Okayama, H. Masubuchi, T. Yonekawa, K. Watanabe, N. Amino and T. Hase. 2000. Loop-mediated isothermal amplification of DNA. Nucleic Acids Research 28:63.

Parida, M., G. Posadas, S. Inoue, F. Hasebe and K. Morita. 2004. Real-time reverse transcription loop-mediated isothermal amplification for rapid detection of West Nile virus. Journal of Clinical Virology 42:257-263.

Parida, M., K. Horioke, H. Ishida, P.K. Dash, P. Saxena, A.M. Jana, M.A. Islam, S. Inoue, N. Hosaka and K. Morita. 2005. Rapid detection and differentiation of dengue virus serotypes by a real-time reverse transcription-loop-mediated isothermal amplification assay. Journal of Clinical Microbiology 43:2895-2903.

Pillai, D., J.R. Bonami and J. Sri Widada. 2006. Rapid detection of Macrobrachium rosenbergii nodavirus (MrNV) and extra small virus (XSV), the pathogenic agents of white tail disease of Macrobrachium rosenbergii (De Man), by loop-mediated isothermal amplification. Journal of Fish Diseases 29:275-283.

Poon, L.L., B.W. Wong, K.H. Chan, S.S. Ng, K.Y. Yuen, Y. Guan and J.S. Peiris. 2005. Evaluation of real-time reverse transcriptase PCR and real-time loop-mediated amplification assays for severe acute respiratory syndrome coronavirus detection. Journal of Clinical Microbiology 43:3457-3459.

Primavera, J.H. and E.T. Quinitio. 2000. Runt-deformity syndrome in cultured giant tiger prawn Penaeus monodon. Journal of Crustacean Biology 20:796-802.

Shike, H., A.K. Dhar, J.C. Burns, C. Shimizu, F.X. Jousset, K.R. Klimpel and M. Bergoin. 2000. Infectious hypodermal and hematopoietic necrosis virus of shrimp is related to mosquito brevidenso viruses. Virology 277:167-177.

Sritunyalucksana, K., J. Srisala, K. McColl, L. Nielsen and T.W. Flegel. 2006. Comparison of PCR testing methods for white spot syndrome virus (WSSV) infections in penaeid shrimp. Aquaculture 255:95-104.

Sun, Z.F., C.Q. Hu, C.H. Ren and Q. Shen, 2006. Sensitive and rapid detection of infectious hypodermal and hematopoietic necrosis virus (IHHNV) in shrimps by loop-mediated isothermal amplification. Journal of Virological Methods 131:41-46.

Syed Musthaq, S., R. Sudhakaran, G. Balasubramanian and A.S. Sahul Hameed. 2006. Experimental transmission and tissue tropism of white spot syndrome virus (WSSV) in two species of lobsters, Panulirus homarus and Panulirus ornatus. Journal of Invertebrate Pathology 93:75-80.

Takahashi, Y., T. Itami, M. Kondo, M. Maeda, R. Fujii, S. Tomonaga, K. Supamattaya and S. Boonyaratpalin. 1994. Electron microscopic evidence of bacilliform virus infection in Kuruma shrimp (Penaeus japonicus). Fish Pathology 29:121-125.

Tang, K.F. and D.V. Lightner. 2001. Detection and quantification of infectious hypodermal and hematopoietic necrosis virus in penaeid shrimp by real-time PCR. Diseases of Aquatic Organisms 44:79-85.

Teng, P.H., C.L. Chen, P.F. Sung, F.C. Lee, B.R. Ou and P.Y. Lee. 2007. Specific detection of reverse transcription-loop-mediated isothermal amplification amplicons for Taura syndrome virus by colorimetric dot-blot hybridization. Journal of Virological Methods 146:317-326.

Wijegoonawardane, P.K., J.A. Cowley, T. Phan, R.A. Hodgson, L. Nielsen, W. Kiatpathomchai and P.J. Walker. 2008. Genetic diversity in the yellow head nidovirus complex. Virology 380:213-225. 
Yoneyama, T., T. Kiyohara, N. Shimasaki, G. Kobayashi, Y. Ota, T. Notomi, A. Totsuka and T. Wakita. 2007. Rapid and real-time detection of hepatitis A virus by reverse transcription loop-mediated isothermal amplification assay. Journal of Virological Methods 145:162-168.

Yuan, L., X. Zhang, M. Chang, C. Jia, S.M. Hemmingsen and H. Dai. 2007. A new fluorescent quantitative PCR-based in vitro neutralization assay for white spot syndrome virus. Journal of Virological Methods 146:96-103. 